\title{
Mouse strain differences in autonomic responses to stress
}

\author{
M. J. V. Van Bogaert ${ }^{*}{ }^{\dagger}$, L. Groenink ${ }^{\dagger}$, R. S. \\ Oosting $^{\dagger}$, K. G. C. Westphal ${ }^{\dagger}$, J. van der Gugten ${ }^{\dagger}$ \\ and B. Olivier ${ }^{\dagger, \ddagger}$ \\ ${ }^{\dagger}$ Department of Psychopharmacology, Utrecht Institute of \\ Pharmaceutical Sciences, Behavioural Genomics Section, \\ Rudolf Magnus Institute of Neuroscience, Utrecht, the \\ Netherlands, and ${ }^{\ddagger}$ Department of Psychiatry, Yale University \\ School of Medicine, New Haven, CT, USA \\ *Corresponding Author: M. van Bogaert, Sorbonnelaan 16, \\ Room W128, 3584 CA Utrecht, the Netherlands. E-mail: \\ m.j.v.vanbogaert@pharm.uu.nl
}

In humans, anxiety disorders are often accompanied by an overactive autonomic nervous system, reflected in increased body temperature (BT) and heart rate (HR). In rodents, comparable effects are found after exposure to stress. These autonomic parameters can give important information on stress and anxiety responses in mice. In the present experiments, stress reactivity of three frequently used mouse strains [129 Sv/Ev, Swiss Webster (SW) and C57 BL/6] was assessed using their autonomic stress responses. $B T, H R$ and activity were telemetrically measured. Undisturbed circadian rhythms already showed clear differences between the mouse strains. Hereafter, autonomic responses to stressors with increasing intensity were measured. Strain differences were found in magnitude and duration of the stress responses, especially after high-intensity stressors. Generally, C57BL/6 mice showed the largest autonomic response, SW the lowest and the 129Sv/Ev the intermediate response. Interestingly, the observed ranking in autonomic stress response does not match the behavioral stress responsivity of these strains. Finally, sensitivity to the anxiolytic diazepam $(0,1,2,4$ and $8 \mathrm{mg} / \mathrm{kg})$ was tested using the stress-induced hyperthermia paradigm. Pharmacological sensitivity to diazepam differed between the strains with the 129Sv/Ev being most sensitive. These studies show that simultaneous measurement of behavioral and autonomic parameters under stressful conditions contributes considerably to a better interpretation of anxiety and stress levels in mice.

Keywords: Anxiety, body temperature, heart rate, strain differences, stress

Received 11 January 2005, revised 18 February 2005, accepted for publication 14 March 2005

doi: 10.1111/j.1601-183X.2005.00143.x
Anxiety disorders are characterized by psychological symptoms like extensive worries and fear of dying and are accompanied by autonomic changes (Finn et al. 2003; Friedman \& Thayer 1998a). In humans, higher anxiety levels seem to correlate with an overactive autonomic nervous system $(A N S)$, reflected in elevated heart rate $(H R)$, increased body temperature (BT) and shortness of breath. In rodents, similar effects are found: following stress, increases in HR and BT are observed (Bouwknecht et al. 2000; Friedman \& Thayer 1998b; Lesch 1991; Nijsen et al. 1998; Olivier et al. 1998). Previously, we have shown that autonomic responses to stressful situations provide valuable information on anxiety levels and pharmacological sensitivity of receptor knockout mice (Pattij et al. 2002). In the search for underlying mechanisms of anxiety and stress disorders, mice are often the species of choice, because of the possibility to use geneticmanipulated mouse models. It is widely acknowledged that differences exist between mouse strains in many behavioral traits, including sensitivity for stress and anxiety. Moreover, differences in pharmacological sensitivity toward anxiolytic drugs are well known (Carola et al. 2002; Crawley et al. 1997; Griebel et al. 2000). Strain differences may underlie ambivalent results of pharmacological treatments in behavioral experiments on anxiety (Crabbe et al. 1999; Wahlsten et al. 2003), where basal levels of anxiety for a large extent determine possible outcomes of such treatments. The genetic background is important if effects of a certain gene mutation are sought, and choice for a basal high- or low-anxiety strain will depend on the direction the gene mutation is expected to affect anxiety. On the other hand, studying functional effects of gene mutations in different backgrounds may lead to unexpected effects, for example in the case of the $5-\mathrm{HT}_{1 \mathrm{~A}}$ receptor knockout mouse in three different background strains. The removal of the $5-\mathrm{HT}_{1 \mathrm{~A}}$ receptor resulted in a decreased sensitivity to some effects of benzodiazepines in only one strain [Swiss Webster (SW)] (Bailey \& Toth 2004 Sibille et al. 2000; Toth 2003).

The present study was performed to obtain more fundamental insight in autonomic parameters like HR and BT and their role in stress and anxiety in different mouse strains. Using radio telemetry, autonomic parameters and locomotor activity (LA) of the animals were measured during all experiments. All the strains used, 129Sv/Ev (129S6), SW and C57 $\mathrm{BI} / 6$ (B6), are strains which are frequently used in anxiety research as background strains; these strains show different response in behavior and activity when observed in anxiety paradigms (Bouwknecht et al. 2004; Rodgers et al. 2002a; 


\section{Van Bogaert et al.}

Rodgers et al. 2002b; Olivier et al. 2003). Using behavioral paradigms, differences between mouse strains have been reported previously, with the 12956 strain being considered a 'high-anxiety' strain and the B6 a 'low-anxiety' strain. Furthermore, activity levels in approach-avoidance paradigms in the 12956 strain was clearly found to be less active compared with the B6 and SW strains (Paulus et al. 1999; Tang et al. 2002). By comparing these three strains using telemetry, more knowledge of autonomic differences and activity on baseline levels, response to stress and pharmacological was gathered. Our data can be used to select the most suitable mouse strains to investigate the role of specific genes in autonomic responses following stress and in anxiety disorders. In the present studies, we first obtained undisturbed parameters by measuring circadian rhythms of BT, HR and LA, followed by measuring the reaction to stressful stimuli with different intensities. Finally, we studied differences in sensitivity toward the anxiolytic diazepam.

\section{Materials and methods}

\section{Subjects}

Groups of 10-12 male mice of different genetic backgrounds (129Sv/Ev Tac, SW and C57BL/6J) were obtained from Taconic M\&B, Ry, Denmark. At surgery, animals weighed at least $25 \mathrm{~g}$. Afterwards, they were housed singly in Macrolon ${ }^{\circledR}$ type 2 cages $(22 \times 16 \times 14 \mathrm{~cm})$, enriched with bedding and nesting material under a 12-h light/12-h dark cycle (lights on from 0600 to $1800 \mathrm{~h}$ ) at controlled temperature $\left(20 \pm 2{ }^{\circ} \mathrm{C}\right)$ and relative humidity (40-50\%) with free access to standard food pellets and tap water. The experiments were carried out with approval of the ethical committee of the Faculties of Pharmaceutical Sciences, Chemistry and Biology, Utrecht University, the Netherlands (DEC DGK) FSB).

\section{Surgery}

Surgery was performed as described by Pattij (Pattij et al. 2002). Radio-telemetry electrocardiogram (ECG) transmitters [type: ETA-F20, Data Sciences International (DSI), St Paul, $\mathrm{MN}$ ] were implanted. After surgery, animals were allowed to recover for 24-48 $\mathrm{h}$ in a separate recovery room with part of the cage placed on a heating pad. When considered necessary, analgesia was given $\left(\right.$ Temgesic $^{\circledR}, 0.3 \mathrm{mg} / \mathrm{ml}$; $1 \mathrm{mg} / \mathrm{kg}$ of (P). To prevent dehydration, the animals were injected twice daily with $1 \mathrm{ml}$ of sterile saline SC for 4 days. During 7 days, the animals had easy access to wetted food pellets, solid energy drink, tap water and normal food pellets inside the cage. Total duration of recovery was 2 weeks; during this period, mice were checked and weighed daily.

\section{Radio telemetry}

The radio-telemetry system is composed of the earliermentioned transmitter, measuring BT and LA, with two flexible leads which measure ECG/HR, a telemetry receiver (model RLA 1020), a data exchange matrix collecting input from receivers, all connected to a computer running Dataquest Art Gold version 2.2. The transmitters are equipped with magnetically activated switches, to turn on/off the device. All equipment and software were obtained from DSI.

\section{Data reduction and statistics}

Data sampling for all experiments started at the afternoon prior to the experiment to obtain undisturbed baseline values. During all experiments, BT $\left({ }^{\circ} \mathrm{C}\right)$ and $\mathrm{HR}$ (beats per minute) data of all animals were gathered during 6 seconds every minute, while LA (counts) was measured continuously during experiments. Circadian rhythm data of 5 undisturbed days were averaged to a single 24-h period for each mouse, after which group values were averaged to time periods of $30 \mathrm{~min}$. For statistical analysis, group values were further averaged to eight blocks of 3-h values, and these data were analyzed by means of repeated measures ANOVA with strains as 'between subject' factor and the 3-h blocks of, respectively, BT, HR and LA as 'within subject' factor. Data reduction in stress response and pharmacological experiments was obtained by averaging data collected over $5 \mathrm{~min}$ to a single value. To measure maximum increase of the parameters, peak values within 30 min after presentation of the stressors were determined using peak finding in Excel. Baseline values were obtained by calculating the average value from 30 to $10 \mathrm{~min}$ before the stressor was presented. To eliminate initial strain differences in baseline values, the increase in BT and HR is obtained by subtracting baseline values from the maximum effect, which results in $\Delta$ values of these parameters, $\Delta \mathrm{BT}$ and $\Delta \mathrm{HR}$. Differences in response to the different stressors within each strain were analyzed using repeated measures ANOVA with increase of the parameters as 'within subject' factor. Differences between the strains were analyzed using one-way ANova. Duration of the effects was obtained in Excel by calculating the amount of minutes needed to return to baseline values after the stressor was presented. Differences within each strain and between the strains in duration were analyzed similar to the $\Delta$ values. In case of statistical significance, Bonferroni's corrected post hoc comparisons were used for subsequent analysis. The level of significance was set at $P<0.05$. All statistical analysis was performed using sPSS for Windows version 10.0 (SPSS, Chicago, IL).

\section{Circadian rhythm and baseline}

During 15 consecutive days BT, HR and LA were recorded. Every other day, a 5-min inspection of animal health, water and food supplies was performed. On day 6, animals 
received a new home cage (similar cage, new bedding). These telemetric data were used to measure novel cage (NC) stress (see Stressful stimuli, NC stress). To obtain undisturbed data only, inspection days were excluded from analysis.

\section{Stressful stimuli}

\section{Disturbance}

Disturbance data were obtained during the inspection days of circadian rhythm measurements by collecting data of BT, $\mathrm{HR}$ and LA before and after the punctual scheduled 5-min inspections at $1000 \mathrm{~h}$. During inspections, each animal was disturbed by tapping the cage until movement of the mouse was observed. For statistical analysis, data of three disturbance periods were averaged to a single period of 5-min blocks.

\section{Handling}

Effects on BT, HR and LA of handling stress were measured using a procedure of picking up the animal for $5-10$ seconds and subsequently returning it to its familiar home cage. The procedure was performed at $1000 \mathrm{~h}$ and completed for all 36 animals within $5 \mathrm{~min}$. Two experimenters were present to execute the procedure in order to reduce time of presence in the animal room and prevent interference of effects of presence in the room.

\section{NC}

To assess effects of novelty on BT, HR and LA during the 6th day of circadian rhythm measurements, the animals were placed into a clean standard macrolon ${ }^{\circledR}$ cage, similar in size to their familiar home cage, provided with clean bedding and tissue.

\section{Stress-induced hyperthermia}

Stress-induced hyperthermia $(\mathrm{SIH})$, observed after a stressor, is mediated by the ANS and results in an increase of BT and HR. It has been found that this increase in autonomic parameters is not subject to habituation. The $\mathrm{SIH}$ paradigm was performed twice a week starting 2 weeks after finishing the circadian rhythm measurements. In the SIH paradigm, mice are exposed to two stressors, with intervals of $1 \mathrm{~min}$ between successive animals. The first stressor is an injection, presented at time -60 min with drug or vehicle, the second stressor is a rectal temperature measurement at time 0 min. For an extensive review on the SIH paradigm, see Olivier et al. (Olivier et al. 2003).

\section{SIH saline}

To measure putative differences between the strains in their autonomic response to injection and rectal temperature measurement, SIH with only saline injections was performed. Data were collected from 60 min before the saline injection until 150 min after the second stressor. The SIH paradigm had two $\Delta$ values for both BT and HR. First, increases after the injection result in $\Delta B T_{1}$ and $\Delta \mathrm{HR}_{1}$; second, increases after rectal temperature measurement result in $\Delta \mathrm{BT}_{2}$ and $\Delta \mathrm{HR}_{2}$.

\section{SIH: diazepam}

Effects of the anxiolytic diazepam on autonomic parameters were investigated. Diazepam was injected in five $(0,1,2,4$ and $8 \mathrm{mg} / \mathrm{kg})$ dosages. Doses and vehicle were randomly given over time to each mouse and each dose. To determine anxiolytic effect of the drugs, $\Delta B T_{2}$ and $\Delta \mathrm{HR}_{2}$ were used. The intrinsic effect of diazepam on basal BT and $H R$ before the rectal temperature measurement was

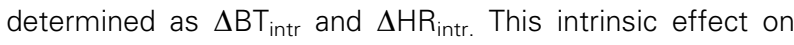
basal $B T$ and basal $H R$ is not part of the stress response but may affect this response. $\Delta \mathrm{BT}_{\text {intr }}$ and $\Delta \mathrm{HR}_{\text {intr }}$ were obtained by subtracting baseline values from the lowest value of BT or HR found for each individual animal before the second stressor is presented.

\section{Results}

\section{Circadian rhythm}

As shown in Fig. 1, diurnal rhythms were present in all strains and for all parameters tested, with lower values of $B T, H R$ and LA during the inactive, lights-on period. Differences were present between the three strains regarding diurnal variation levels over the eight 3-h time blocks in all parameters tested, and main differences will be described below.

$B T$

During the inactive period, strains differed significantly in BT $\left(F_{2,30}=34.89, P<0.001: \mathrm{SW}>129 \mathrm{~S} 6>\mathrm{B} 6\right)$. During the active period, BT was more comparable among the strains, although differences were found when comparing means over the complete active period $\left(F_{2,30}=4.2, \quad P=0.03\right.$; $\mathrm{SW}>12956)$. Differences between the active-inactive periods were most profound in the $\mathrm{C} 57$ mice, mainly due to their low BT during the inactive period.

$H R$

In general, HR was similar in all strains, both during active and inactive periods, although during the start of the active period the SW strain showed no anticipatory peak response, and in this strain, HR decreased before lights were turned on to initiate the inactive period.

LA

The SW strain was most active during the inactive period the SW strain was most active $\left(F_{2,30}=17, \quad P<0.001\right.$; $\mathrm{SW}>129 \mathrm{~S} 6=\mathrm{B} 6)$; $\mathrm{SW}$ and B6 mice showed comparable activity during the active period, both strains being more 

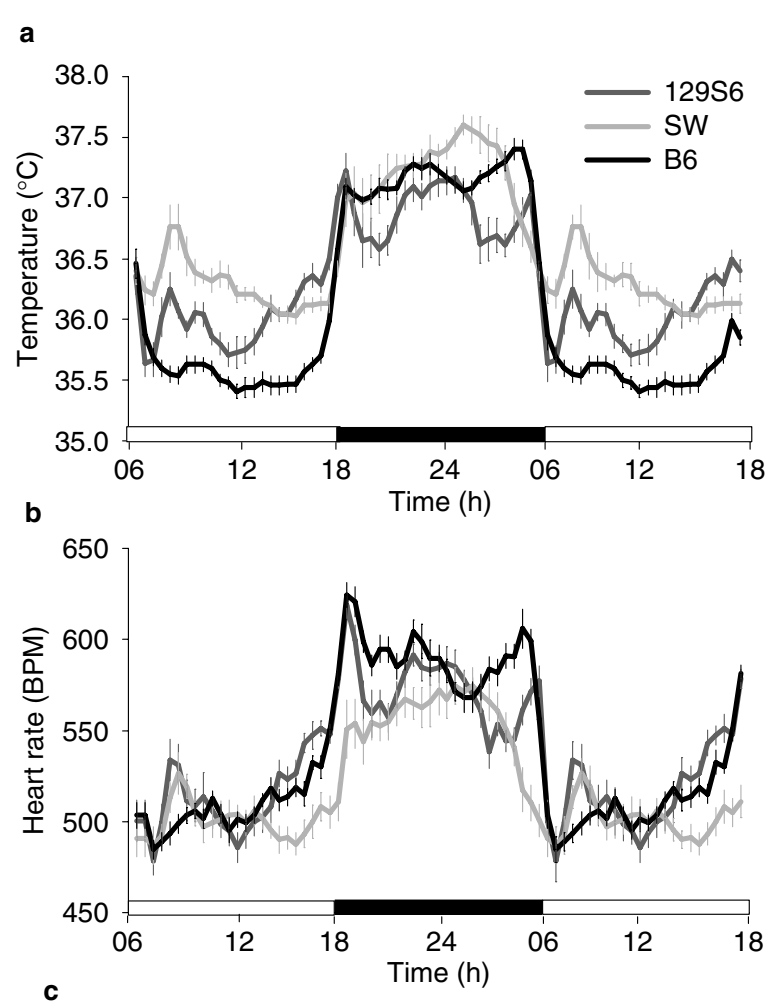

c

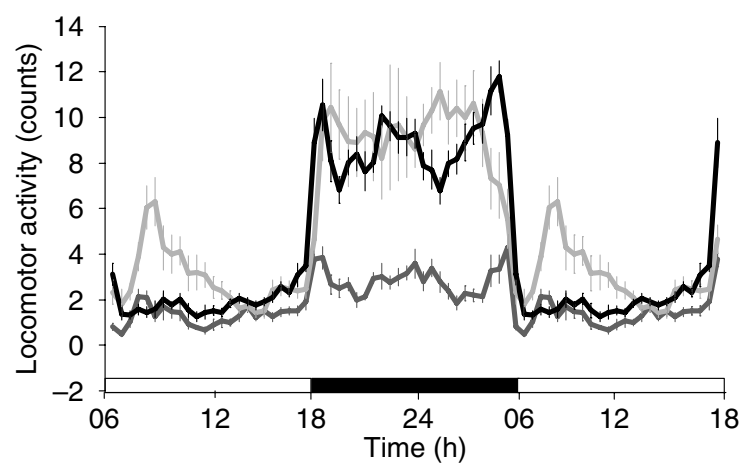

Figure 1: Circadian rhythm of body temperature (BT) (a), heart rate (HR) (b) and locomotor activity (LA) (c) over a 12-h light/12-h dark cycle (lights on from 0600 to $1800 \mathrm{~h}$ ) mean values of 7 days in 129S6 (dark gray, $n=10$ ), Swiss Webster (SW) (light gray, $n=11$ ) and $B 6$ (black, $n=12$ ) mice. Data represent mean group values of 30-min blocks \pm SEM. Circadian rhythm is found in all strains and in all parameters (BT: 129S6, $F_{7,3}=258, \quad P<0.001 ; \quad S W, \quad F_{7,4}=38.4, \quad P=0.002 ; \quad B 6$, $F_{7,5}=182.1, P=<0.001$ ) (HR: 129S6, $F_{7,3}=10.3, P=0.041$; SW $F_{7.4}=7.6, P=0.034 ; B 6, F_{7.5}=13.5, P=0.006$ ) (LA: 129S6, $F_{7,3}=12.1, \quad P=0.033 ; \quad S W, \quad F_{7,4}=48.2, \quad P=0.001 ; \quad B 6$, $\left.F_{7,5}=104, P<0.001\right)$. Strain differences are found in all parameters (BT: $F_{14,50}=11.6, \quad P<0.001, \quad \mathrm{HR}: \quad F_{14,50}=5.7$, $P<0.001$ and $\left.L A: F_{14,50}=9.2, P<0.001\right)$.

active than $129 S 6$ mice $\left(F_{2,30}=14.7, \quad P<0.001\right.$; $\mathrm{SW}=\mathrm{B} 6>129 \mathrm{~S} 6)$. The $\mathrm{B} 6$ and the $129 \mathrm{~S} 6$ strains showed comparable low activity during the inactive period.

\section{Effects of stress: between strain differences}

Table 1 summarizes $\Delta$ values of BT, HR and LA after presentation of the various stressors, and relevant responses and differences are described below.

\section{Disturbance stress}

Figure 2 shows the response after disturbance stress, a mild-intensity stressor, during the inactive period with significant increase in $B T, H R$ and $L A$ in all strains. No strain differences were observed in BT increase and duration, while increase in HR of the $129 \mathrm{~S} 6$ strain was less than in the other strains. In LA, the SW strain showed both more activity and during a longer period of time.

\section{Handling stress}

Figure 3 shows the effects of this intermediate-intensity stressor, with no strain differences found in BT and HR. LA results again show the least amount of increase in the $129 S 6$ strain, while duration of activity was longest in the SW mice.

\section{SIH}

Figure 4 shows the effect on all parameters both after injection (first stressor) and after rectal temperature measurement (second stressor). There were no strain differences in HR; however, BT showed higher increase in the $129 \mathrm{~S} 6$ strain with less LA found in this strain.

\section{NC stress}

Many differences between the strains were found after presentation of the most intense stress: cage changing (Fig. 5). Differences between all strains were found in BT (B6 > 129S6 > SW), while HR in the B6 strain was increased $(B 6>S W=129)$. Analysis of NC on BT duration demonstrated that $129 S 6$ mice showed the fastest return to baseline, while SW and B6 mice needed equal time for BT to return to baseline values. While LA lasted longer in the SW strain, HR returned to normal values after a short time in this strain. When observing LA, the $129 S 6$ mice again showed least increase ( $B 6=S W>129 S 6)$.

\section{Effects of stress: within strain differences}

In addition to the differences between the three strains, differences within each strain after the various stressors, disturbance (D), handling $(\mathrm{H})$, SIH and $\mathrm{NC}$, were found.

\section{6}

Higher intensity of stress resulted in more increase in BT although not significant between $\mathrm{SIH}$ stress and NC stress $\left(F_{3,4}=11.8, P=0.04, \mathrm{D}<\mathrm{H}<\mathrm{SIH}=\mathrm{NC}\right)$. Similar effects were found in HR and LA; however, no significant differences in increase between handling and $\mathrm{SIH}$ stress were found $\left(\mathrm{D}<\mathrm{H}=\mathrm{SIH}<\mathrm{NC}\right.$; HR: $F_{3,4}=20.9, P=0.007$; LA: $F_{3,4}=38.7, P=0.002$. 
Table 1: Maximum effect on BT, HR and LA of the various stressors, duration of the effect and statistical differences between three mouse strains

\begin{tabular}{|c|c|c|c|c|c|}
\hline Stressor & $129 S 6$ & SW & B6 & Strain differences & $P$ value \\
\hline \multicolumn{6}{|c|}{ Disturbance } \\
\hline \multicolumn{6}{|c|}{ Maximum increase } \\
\hline BT & $0.8 \pm 0.1$ & $0.9 \pm 0.1$ & $0.7 \pm 0.06$ & $129 S 6=S W=B 6$ & $0.61 \mathrm{NS}$ \\
\hline $\mathrm{HR}$ & $94 \pm 13$ & $139 \pm 14$ & $164 \pm 15$ & $129 \mathrm{~S} 6<\mathrm{SW}=\mathrm{B} 6^{*}$ & 0.01 \\
\hline LA & $1.7 \pm 0.6$ & $9.2 \pm 1.8$ & $5.3 \pm 0.9$ & $129 \mathrm{~S} 6=\mathrm{B} 6<\mathrm{SW}^{*}$ & $<0.001$ \\
\hline \multicolumn{6}{|l|}{ Handling } \\
\hline \multicolumn{6}{|c|}{ Maximum increase } \\
\hline BT & $2.0 \pm 0.3$ & $1.7 \pm 0.2$ & $1.8 \pm 0.1$ & $129 S 6=S W=B 6$ & $0.52 \mathrm{NS}$ \\
\hline $\mathrm{HR}$ & $213 \pm 25$ & $227 \pm 37$ & $236 \pm 15$ & $129 S 6=S W=B 6$ & $0.85 \mathrm{NS}$ \\
\hline LA & $8.4 \pm 1.5$ & $16.9 \pm 2.0$ & $13.3 \pm 0.9$ & $129 \mathrm{~S} 6<\mathrm{SW}=\mathrm{B} 6^{*}$ & $<0.001$ \\
\hline \multicolumn{6}{|c|}{ Duration } \\
\hline BT & $54 \pm 4$ & $64 \pm 7$ & $56 \pm 4$ & $129 S 6=S W=B 6$ & $0.39 \mathrm{NS}$ \\
\hline $\mathrm{HR}$ & $27 \pm 5$ & $40 \pm 6$ & $33 \pm 3$ & $129 S 6=S W=B 6$ & $0.17 \mathrm{NS}$ \\
\hline LA & $25 \pm 3$ & $45 \pm 5$ & $28 \pm 2$ & $129 \mathrm{~S} 6=\mathrm{B} 6<\mathrm{SW}^{*}$ & 0.001 \\
\hline \multicolumn{6}{|c|}{$\mathrm{SIH}$ injection } \\
\hline \multicolumn{6}{|c|}{ Maximum increase } \\
\hline BT & $2.4 \pm 0.2$ & $1.8 \pm 0.07$ & $1.9 \pm 0.1$ & $\mathrm{SW}=\mathrm{B} 6<129 \mathrm{~S} 6^{*}$ & 0.04 \\
\hline $\mathrm{HR}$ & $216 \pm 14$ & $187 \pm 14$ & $194 \pm 8$ & $129 S 6=S W=B 6$ & $0.29 \mathrm{NS}$ \\
\hline LA & $10.8 \pm 1.1$ & $16.9 \pm 1.5$ & $13.3 \pm 0.9$ & $129 S 6<\mathrm{SW}=\mathrm{B} 6^{*}$ & $<0.001$ \\
\hline \multicolumn{6}{|c|}{ SIH stressor } \\
\hline \multicolumn{6}{|c|}{ Maximum increase } \\
\hline BT & $1.7 \pm 0.1$ & $1.3 \pm 0.08$ & $1.2 \pm 0.07$ & $\mathrm{SW}=\mathrm{B} 6<129 \mathrm{~S} 6^{*}$ & $<0.001$ \\
\hline $\mathrm{HR}$ & $215 \pm 8$ & $222 \pm 12$ & $219 \pm 9$ & $129 S 6=S W=B 6$ & $0.27 \mathrm{NS}$ \\
\hline LA & $10.9 \pm 0.8$ & $18.4 \pm 1.3$ & $16.8 \pm 0.9$ & $129 \mathrm{~S} 6<\mathrm{SW}=\mathrm{B} 6^{*}$ & 0.02 \\
\hline \multicolumn{6}{|c|}{ Duration } \\
\hline BT & $76 \pm 4$ & $79 \pm 3$ & $80 \pm 4$ & $129 S 6=S W=B 6$ & 0.84 NS \\
\hline $\mathrm{HR}$ & $58 \pm 5$ & $48 \pm 3$ & $50 \pm 3$ & $129 S 6=S W=B 6$ & 0.09 NS \\
\hline LA & $28 \pm 1$ & $42 \pm 5$ & $33 \pm 2$ & $129 \mathrm{~S} 6=\mathrm{B} 6<\mathrm{SW}^{*}$ & $<0.001$ \\
\hline \multicolumn{6}{|l|}{ NC } \\
\hline \multicolumn{6}{|c|}{ Maximum increase } \\
\hline BT & $2.5 \pm 0.2$ & $2.0 \pm 0.1$ & $2.6 \pm 0.1$ & $\mathrm{SW}<129 \mathrm{~S} 6=\mathrm{B} 6^{*}$ & $<0.001$ \\
\hline $\mathrm{HR}$ & $211 \pm 49$ & $214 \pm 21$ & $273 \pm 34$ & $\mathrm{SW}<\mathrm{B} 6^{*}+\dagger$ & 0.002 \\
\hline LA & $18.4 \pm 1.2$ & $35.8 \pm 2.6$ & $45.7 \pm 2.5$ & $129 \mathrm{~S} 6<\mathrm{B} 6<\mathrm{SW}^{*}$ & $<0.001$ \\
\hline \multicolumn{6}{|c|}{ Duration } \\
\hline BT & $93 \pm 7$ & $129 \pm 6$ & $129 \pm 6$ & $129 \mathrm{~S} 6<\mathrm{SW}=\mathrm{B} 6^{*}$ & $<0.001$ \\
\hline $\mathrm{HR}$ & $55 \pm 6$ & $33 \pm 3$ & $70 \pm 9$ & $\mathrm{SW}<\mathrm{B} 6 \dagger$ & 0.002 \\
\hline LA & $44 \pm 5$ & $118 \pm 5$ & $85 \pm 6$ & $129 \mathrm{~S} 6<\mathrm{B} 6<\mathrm{SW}^{*}$ & $<0.001$ \\
\hline
\end{tabular}

BT, body temperature; HR, heart rate; LA, locomotor activity; SW, Swiss Webster, NC, novel cage; SIH, stress-induced hyperthermia. Results for maximum increase are group means $\pm \mathrm{SEM}$ in ${ }^{\circ} \mathrm{C}(\mathrm{BT})$, BPM (HR) and counts (LA) for all three strains. Duration of the effect in minutes represents the time needed to return to baseline values. Differences in response between the mouse strains are reflected by both strain differences and $P$ values.

${ }^{*} P<0.05$ differences between strains in response to stress.

${ }^{\dagger}$ Only two strains are listed. The third strain, B6, did not significantly differ from the two mentioned strains.

SW

Increase in BT was similar after handling, SIH and NC stress, which were all higher compared with disturbance stress $\left(F_{3,8}=42.5, P<0.001 ; \mathrm{D}<\mathrm{H}=\mathrm{SIH}=\mathrm{NC}\right)$. Increase in $\mathrm{HR}$ showed no difference between the stressors presented $\left(F_{3,8}=4.8, P=0.5 ; \mathrm{D}=\mathrm{H}=\mathrm{SIH}=\mathrm{NC}\right)$. Effects in LA were increased parallel to higher intensities of the stressor $\left(F_{3,8}=42.5, P<0.001 ; \mathrm{D}<\mathrm{H}=\mathrm{SIH}<\mathrm{NC}\right)$.
B6

Higher increase in both BT and LA was found with increasing intensity of stress (BT: $F_{3,9}=150.4, \quad P<0.001$; LA: $F_{3,9}=65, \quad P<0.001 ; \quad \mathrm{D}<\mathrm{H}=\mathrm{SIH}<\mathrm{NC}$. Disturbance stress resulted in a smaller increase in $\mathrm{HR}$ when compared with the other, more intense stressors $\left(F_{3,9}=5.2, P=0.03\right.$; $\mathrm{D}<\mathrm{H}=\mathrm{SIH}=\mathrm{NC}$ ). 

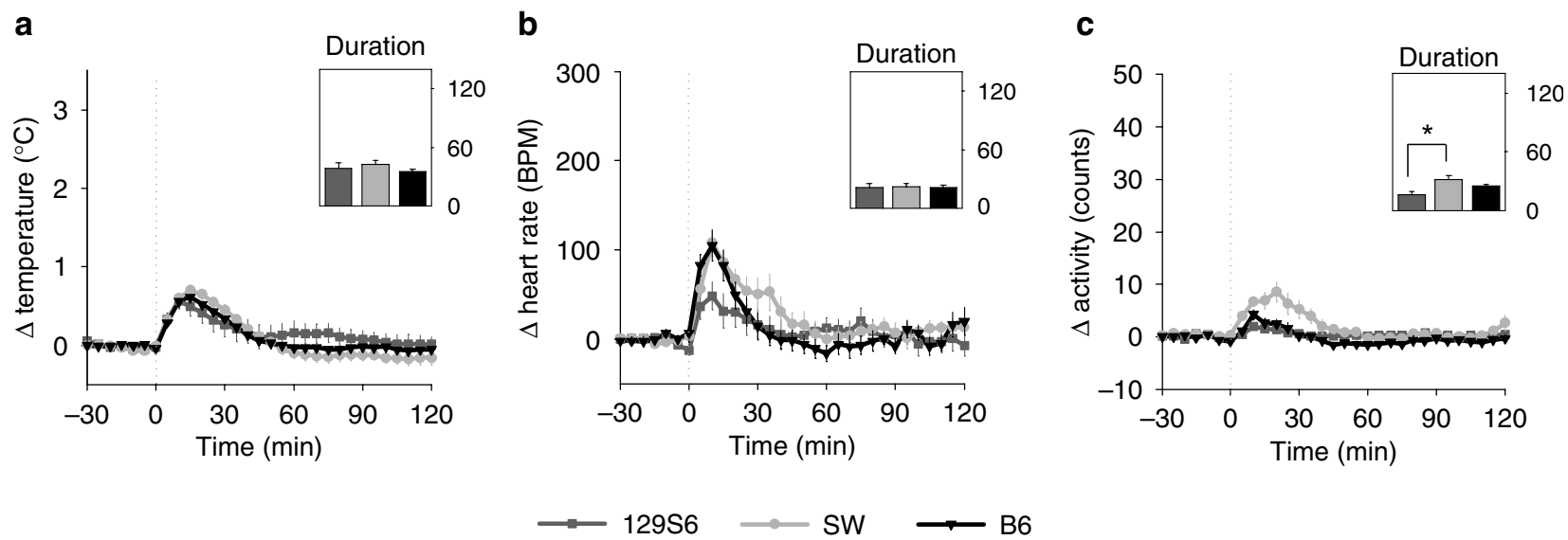

Figure 2: Effects of disturbance stress on body temperature (BT), heart rate (HR) and locomotor activity (LA) and duration of the effect $(\mathbf{m i n})$ in three strains of mice. Mouse strains used are $129 S 6$ (dark gray, $n=10$ ), Swiss Webster (SW) (light gray, $n=11$ ) and B6 (black, $n=12$ ). Disturbance stress consists of entering the room, tapping on the cage until movement of animal is observed. Significant increase in all parameters is found in all strains tested, (a) BT (129S6: $F_{1,9}=45.3, P<0.001 ;$ SW: $F_{1,10}=52, P<0.001$; B6: $\left.F_{1,11}=135.4, P<0.001\right)$; (b) HR (129S6: $\left.F_{1,9}=55.4, P<0.001 ; \mathrm{SW}: F_{1,10}=100.2, P<0.001 ; \mathrm{B} 6: F_{1,11}=117.5, P<0.001\right)$ and (c) LA (129S6: $F_{1,9}=55.4, P<0.001$; SW: $\left.F_{1,10}=25.5, P=0.001 ; \mathrm{B} 6: F_{1,11}=37.7, P<0.001\right)$. No strain differences in BT are found, and in HR and LA, less increase in $129 \mathrm{~S} 6$ mice is found.
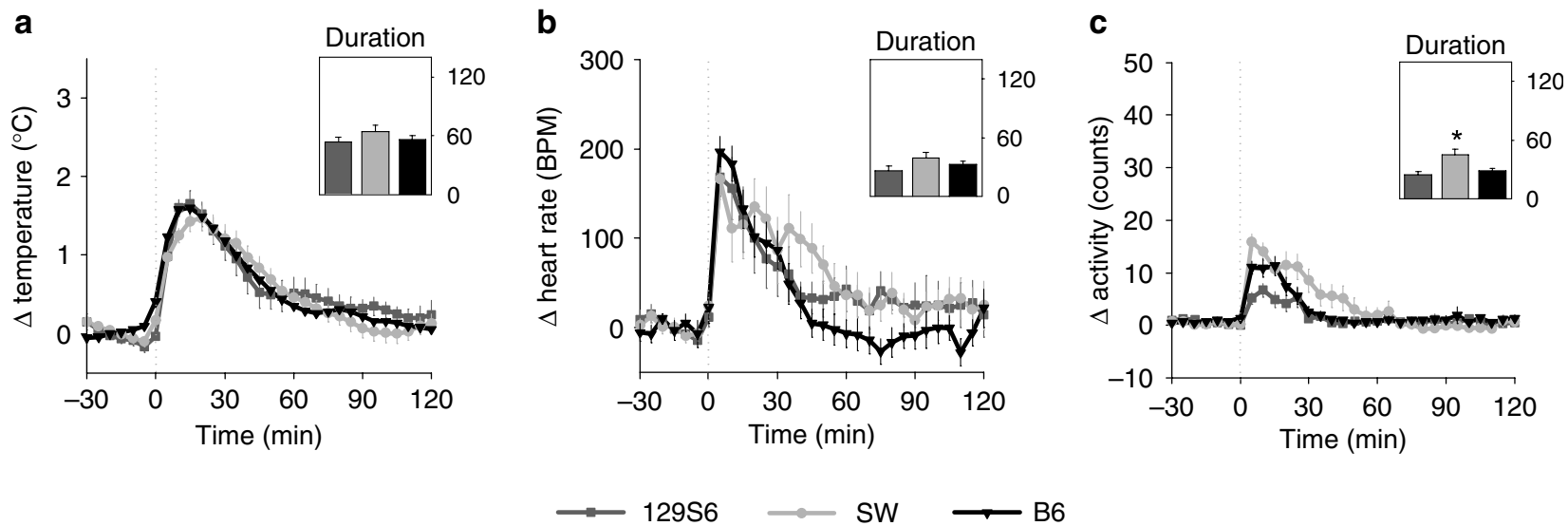

Figure 3: Effects of handling stress, obtained by opening the cage, picking up the animal by its tail for 5 seconds and returning it into its familiar cage. Mouse strains used are 129 S6 (dark gray, $n=10$ ), Swiss Webster (SW) (light gray, $n=11$ ) and B6 (black, $n=12)$. Significant increase is found in all parameters and all strains tested, (a) body temperature (129S6: $F_{1,8}=59.1, P<0.001 ;$ SW: $\left.F_{1,10}=99.3, P<0.001 ; \mathrm{B} 6: F_{1,11}=200.2, P<0.001\right)$; (b) heart rate $\left(129 S 6: F_{1,9}=70.2, P=<0.001 ;\right.$ SW: $F_{1,10}=37.4, P<0.001$; B6: $\left.F_{1,11}=164.3, P<0.001\right)$ and (c) locomotor activity (LA) (129S6: $F_{1,9}=33.3, P<0.001 ;$ SW: $F_{1.10}=72.8, P<0.001 ; B 6$ : $\left.F_{1,11}=105.4, P<0.001\right)$. Differences between the strains are only observed in LA, with less increase in $129 S 6$ mice.

\section{SIH and diazepam}

Figure 6 shows effects of diazepam on $\mathrm{SIH}$; effects and strain differences will be described below.

\section{Effects on BT}

No difference between the strains was found in increase of $\mathrm{BT}\left(\Delta \mathrm{BT} \mathrm{T}_{1}\right)$ after injection of the vehicle, but a significant decrease in $\Delta B T_{1}$ was found in all strains after injection of 4 and $8 \mathrm{mg} / \mathrm{kg}$ of diazepam. Diazepam only decreased basal BT in the $129 \mathrm{~S} 6 \mathrm{strain}$; after the 4 and $8 \mathrm{mg} / \mathrm{kg}$ dosages, the initial increase $\left(\Delta \mathrm{BT}_{1}\right)$ had disappeared $\left(F_{4,6}=8.5, P=0.01\right)$. The anxiolytic effects of diazepam on $\mathrm{SIH}\left(\Delta \mathrm{BT}_{2}\right)$ were different in all strains, the $129 \mathrm{~S} 6$ being most sensitive $\left(F_{4,6}=20.136, P=0.001\right)$ with a decrease in $\Delta \mathrm{BT}_{2}$ found after all dosages of diazepam. Increase in BT after the rectal measurement in SW and B6 mice could not be blocked completely by diazepam; however, in both strains, decrease in $\Delta \mathrm{B} T_{2}$ was observed after injection of 2,4 and $8 \mathrm{mg} / \mathrm{kg}$ of diazepam (SW: $F_{4,7}=9.66, P=0.006 ; \mathrm{B} 6: F_{4,8}=9.917$, $P=0.003)$. 

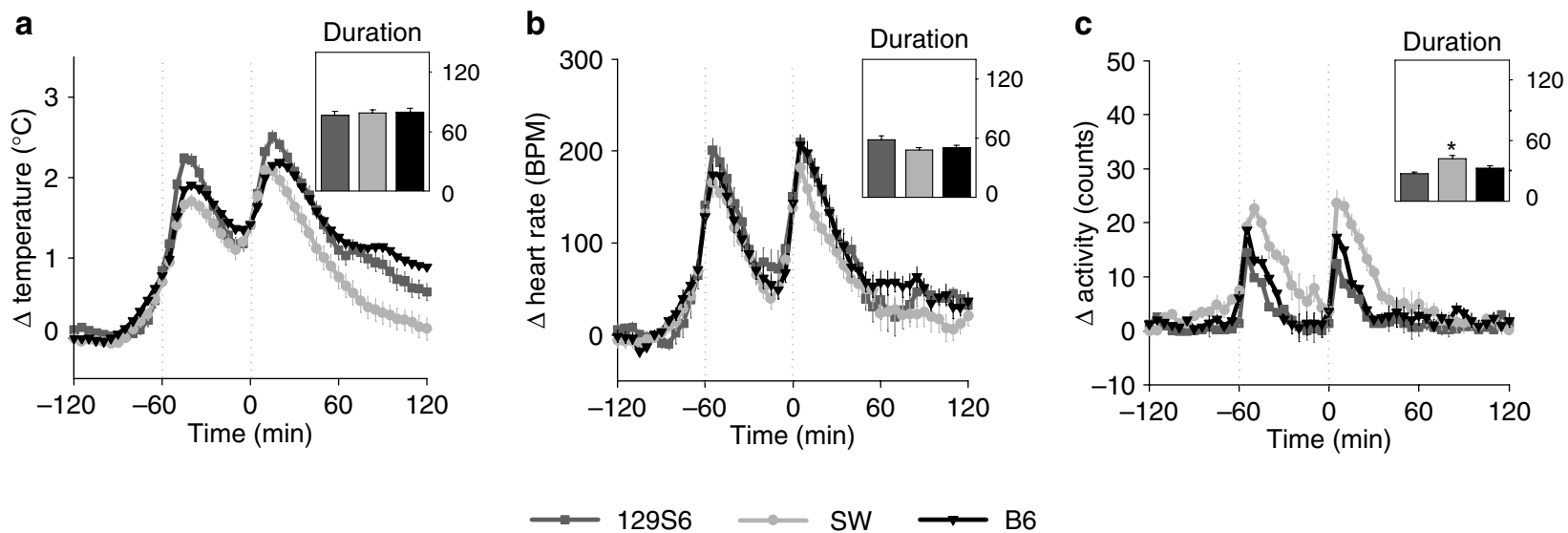

Figure 4: The stress-induced hyperthermia paradigm consists of a saline injection at $\mathbf{- 6 0}$ min and a stressor (rectal temperature measurement) at $\mathbf{0} \mathbf{~ m i n}$, mice are injected with 1-min intervals. Mouse strains used are 129S6 (dark gray, $n=10$ ), Swiss Webster (SW) (light gray, $n=11$ ) and B6 (black, $n=12$ ). Significant increase in all parameters is found in all strains tested, both after injection and after rectal temperature measurement: (a) [body temperature (BT): injection: 129S6: $F_{1,8}=185.4, P<0.001$, SW: $F_{1,10}=482, P<0.001, \mathrm{~B} 6: F_{1,11}=454.1, P<0.001$ and rectal: 129S6: $F_{1,8}=182.9, P<0.001, \mathrm{SW}: F_{1,10}=343.2, P<0.001, \mathrm{~B} 6$ : $F_{1,11}=238.4, P<0.001$; (b) heart rate (HR): injection: 129S6: $F_{1,8}=242.1, P<0.001$, SW: $F_{1,10}=180.1, P<0.001, \mathrm{~B} 6: F_{1,11}=556$, $P<0.001$ and rectal: 129S6: $F_{1,8}=181.1, P<0.001$, SW: $F_{1,10}=129.1, P<0.001, \mathrm{~B} 6: F_{1,11}=729.2, P<0.001$; (c) locomotor activity (LA): injection: 129S6: $F_{1,8}=48.5, P<0.001$, SW: $F_{1,10}=72.4, P<0.001$, B6: $F_{1,11}=92.6, P<0.001$ and rectal: $129 S 6$ : $F_{1,8}=107.3, P<0.001$, SW: $\left.F_{1,10}=131.7, P<0.001, B 6: F_{1,11}=181.5, P<0.001\right]$. No strain differences are found in HR values, increase of BT after injection and after the stressor is significantly increased, while less LA is observed in the $129 \mathrm{~S} 6$ strain.
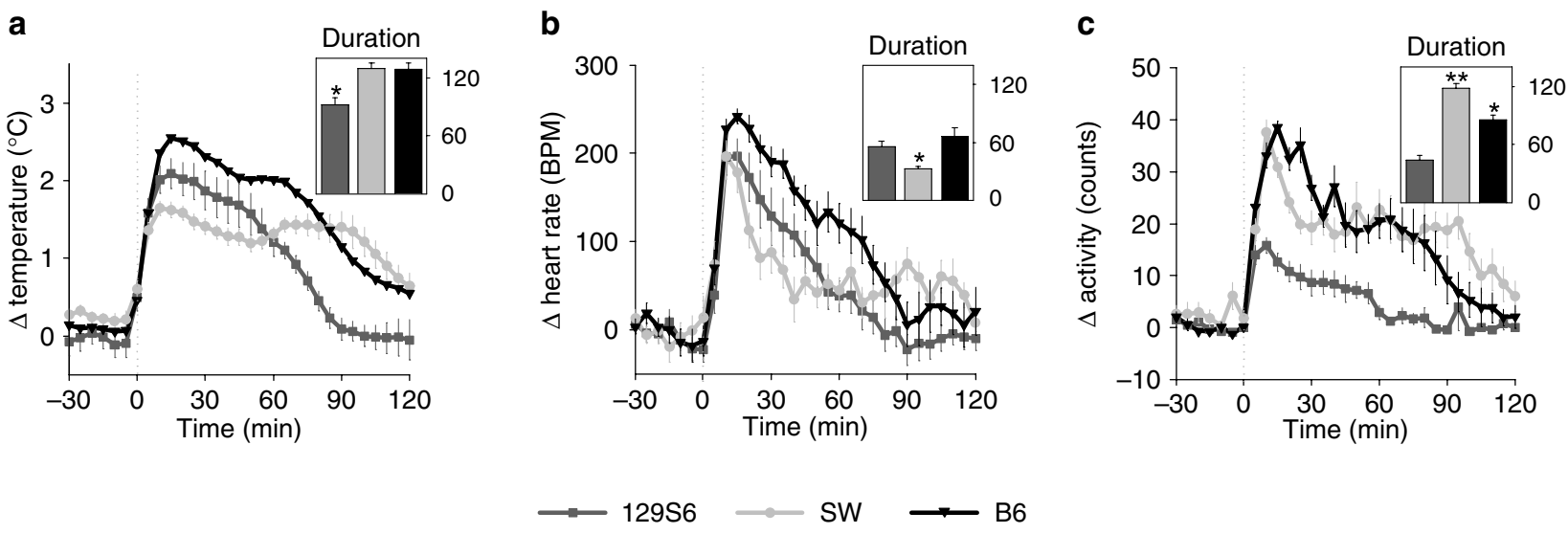

Figure 5: Novel cage stress is obtained by opening the cage, picking up the animal by its tail for $\mathbf{5}$ seconds and returning it into a new, unfamiliar cage with bedding. Mouse strains used are $129 S 6$ (dark gray, $n=10$ ), Swiss Webster (SW) (light gray, $n=11$ ) and B6 (black, $n=12$ ). Significant increase in all parameters is found in all strains tested, (a) body temperature (BT) (129S6: $F_{1,9}=191.2, P<0.001$, SW: $F_{1,10}=184.8, P<0.001, \mathrm{~B} 6: F_{1,11}=537.2, P<0.001$ ); (b) heart rate $(\mathrm{HR})\left(129 \mathrm{S6}: F_{1,9}=335.9, P<0.001, \mathrm{SW}: F_{1,10}=107.9\right.$, $\left.P<0.001, \mathrm{~B} 6: F_{1,11}=426.1, P<0.001\right)$ (c) and locomotor activity (LA) (129S6: $F_{1,9}=222.5, P<0.001, S W: F_{1,10}=107.9, P<0.001$, B6: $\left.F_{1,11}=337.6, P<0.001\right)$. Strain differences are found in all parameters, with BT differences between all strains (B6 $\left.>129 S 6>\mathrm{SW}\right)$, increase in $\mathrm{HR}$ is highest in B6 and $129 \mathrm{~S} 6$ show least increase in LA. Data represent mean group values of 5-min blocks \pm SEM.

\section{Effects on HR}

The highest dose of diazepam $(8 \mathrm{mg} / \mathrm{kg})$ reduced the increase of $\mathrm{HR}$ after injection $\left(\Delta \mathrm{HR}_{1}\right)$ in all strains when compared with vehicle injection $\left(F_{4,25}=4.725, P=0.006\right)$. When analyzing the anxiolytic effect of diazepam, diazepam reduced $\Delta \mathrm{HR}_{2}$ in all strains with the $129 \mathrm{~S} 6$ strain again being the most sensitive and B6 mice least sensitive (129S6:
$F_{4,6}=93.856, P<0.0001 ; S W: F_{4,7}=27.787, P=0.001$; B6: $\left.F_{4,8}=5.085, P=0.025\right)$.

\section{Discussion}

In humans, ANS changes like BT dysregulation (Iverson et al. 2002; Lesch 1991) and increased HR (Friedman \& Thayer 


\section{Van Bogaert et al.}
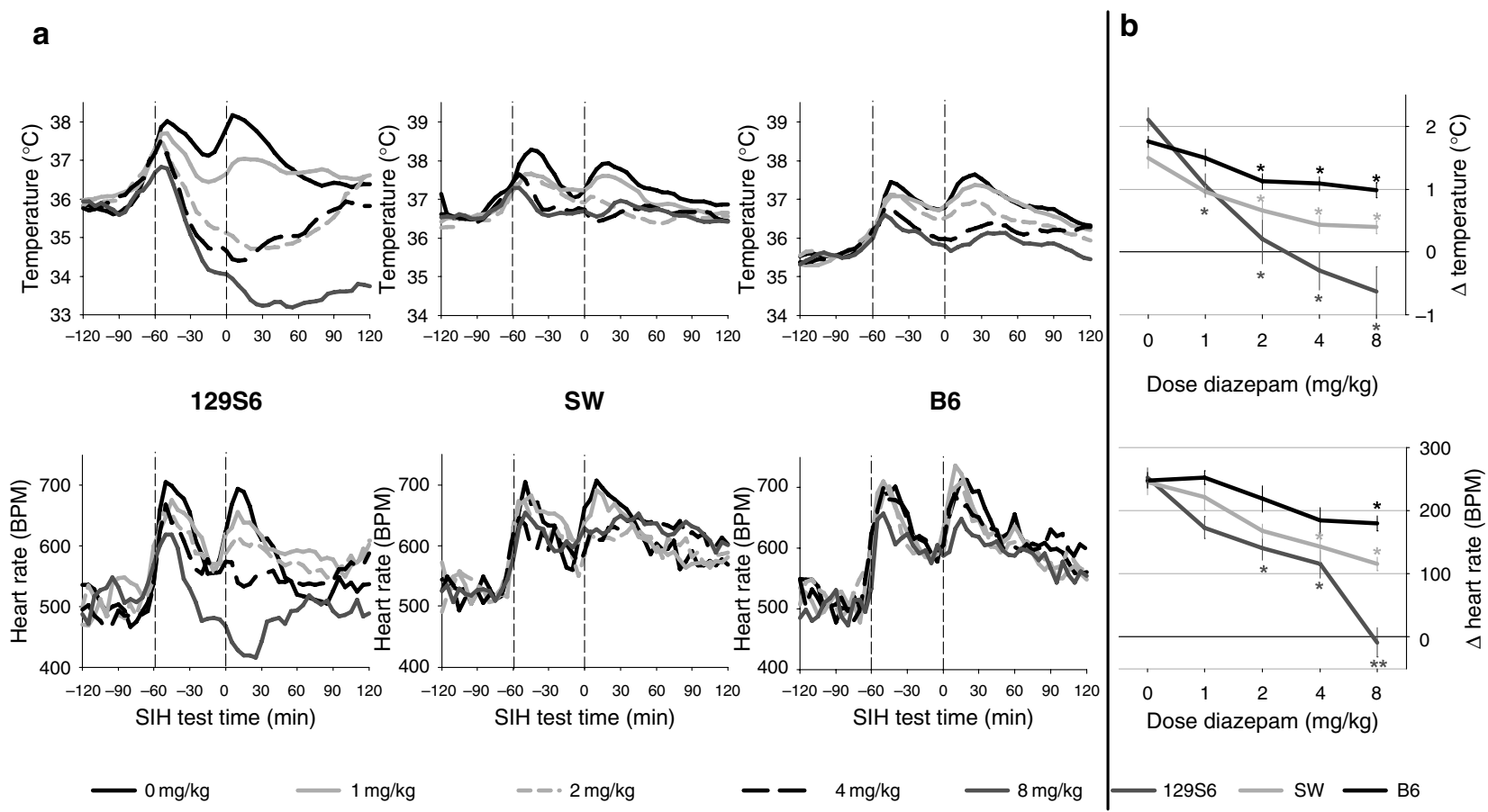

Figure 6: Effects of diazepam $(1,2,4,8 \mathrm{mg} / \mathrm{kg})$ and vehicle $(0 \mathrm{mg} / \mathrm{kg})$ treatment (IP) on stress-induced hyperthermia (SIH). (a) Telemetric data of the effects of injection and the rectal temperature procedure (SIH) on body temperature (BT) and heart rate (HR) in three strains of mice (129S6, $n=10$; SW, $n=11$; B6, $n=12$ ). Times of injection ( $-60 \mathrm{~min}$ ) and rectal temperature measurement (0 $\mathrm{min}$ ) are indicated by vertical lines. Data represent mean group values, averaged over 5-min periods. For clarity, no SEM is present. (b) $\Delta \mathrm{BT}_{2}$ and $\Delta \mathrm{HR}_{2}$ after $\mathrm{SIH}$, representing the increase in $\mathrm{BT}$, respectively, $\mathrm{HR}$ after presentation of the rectal stressor (time $=0$ min). ${ }^{*} P<0.05$ compared to vehicle treatment for the individual mouse strains, ${ }^{*}$ indicates $P<0.05$ compared to the lower dosages (129S6 dark gray*; SW light gray* and B6 black*).

1998a) are part of anxiety and stress disorders. Loss of normal ANS control is present in patients suffering from major depression and anxiety disorders and seems to be the result of changes in sympathetic activation and/or vagal withdrawal (Friedman \& Thayer 1998a; Nijsen et al. 1998; Tulen et al. 1996). Because of these changes in autonomic parameters during stress and anxiety, BT and HR are important parameters to measure together with behavior in the study of depression/anxiety disorders in laboratory animals.

Abnormalities in circadian rhythms have been reported to occur in patients with affective disorders (Goodwin et al. 1982; Wehr \& Wirz-Justice 1982). Similarly, in rodents, it has been shown that stressful events can induce changes in circadian rhythms (Meerlo et al. 1996). The present experiments in the three strains of mice show normal diurnal circadian rhythm in baseline BT, HR and LA with higher values of all parameters during the active, lights-off period. Despite normal circadian rhythms in all strains, differences between the strains are found in all parameters. The environmental temperature during the experiments was set around $21^{\circ} \mathrm{C}$, which is clearly below the metabolic thermo neutral zone of mice (Overton \& Williams 2004; Williams et al. 2002). For the mice to keep their normothermic core temperature, metabolic rate has to be increased to generate enough body heat to compensate for heat losses. Thermoregulation processes are modulated by several factors, and besides exposure to cold and heat, a variety of pathophysiological situations can affect BT (Ricquier \& Bouillaud 2000). We assume that the basal BT measured during the undisturbed circadian rhythm measurements reflects the strain-specific core BTs regulated on a predetermined set point. Some of the strain differences found in BT could partially be explained by strain differences in activity levels and body weight. The SW strain, during the lights-on period, shows higher activity levels which could result into higher BT. Also, the SW is an outbred strain, associated with higher body weight. Generally, with higher body weight, a lower HR can be expected (Mortola \& Lanthier 2004). However, activity and body weight do not account for all differences observed in BT and HR. At the end of the inactive period, $L A$ is similar in all strains with remaining differences in BT; this probably reflects different setpoints in core BT of the three strains.

Another illustration that activity does not account for all differences in HR and BT is the small increase in LA of the $129 S 6$ strain during the active period, while increases in BT and HR are similar to the other strains. In several studies, 12956 mouse strains show little activity when compared 
with 'high activity' strains like B6 (Contet et al. 2001; Homanics et al. 1999; Kelly et al. 1998), although differences in activity between 129 substrains have been found as well (Montkowski et al. 1997). We assume that strain differences in basal BT and HR, as found in the circadian rhythm experiments, will not complicate experiments based on stressinduced elevation of autonomic parameters.

In the second part of the experiments, the response of the three mouse strains to stress was compared, both in autonomic parameters and activity. Generally, it is accepted that mouse strain differences exist in anxiety-related paradigms (Connolly \& Lynch 1981; Griebel et al. 2000; Kim et al. 2002), and in several studies, it has been demonstrated that stress induces elevation in HR (Bouwknecht et al. 2000; Nijsen et al. 1998) as well as increases in BT (Bouwknecht et al. 2000; Olivier et al. 1998). The present experiments show that strain differences are present in stress response when measuring autonomic parameters and activity levels. First, independent of the strain tested, a stressor with higher intensity results into stronger increase in all parameters. Furthermore, time needed to return to baseline values, the duration of the effect, is increased with high-intensity stressors (i.e. NC stress). The least intense stress, disturbance stress, already led to differences in response between the three strains. Differences between the strains became more pronounced, as the intensity of the stressor was increased.

Most data published on anxiety and strain differences are results from behavioral experiments, usually without inclusion of autonomic parameters. Lack of behavioral response by the $129 S 6$ strain, represented in our studies by LA, is not found only after presentation of stress. Even though undisturbed baseline LA values show a significant increase during the active period, the activity level remains low during this period. However, this small behavioral response does not imply that this strain is insensitive to stressful events, for increases in BT and HR after stress are similar or even higher than in the other strains. The SW strain on the other hand shows highest increase in LA, with relatively small increases in autonomic parameters. This might indicate that the SW strain is not an anxious but rather a more explorative and active strain and that the enhanced $\mathrm{BT}$ and $\mathrm{HR}$ responses are mainly results of the increased $L A$. Conclusions on stressresponse levels of the $\mathrm{B} 6$ strain are more ambiguous. This strain shows high increases in autonomic parameters, while LA is low (disturbance stress), intermediate (handling and injection stress) or high (NC stress), indicating that both behavior and physiology are effective measures to investigate stress response in this strain.

Ever since the early 1960s, benzodiazepines, like diazepam, have been used to treat anxiety disorders. The mechanism of action is via modulation of the $\mathrm{GABA}_{A}$ receptor, and it is known that subunit composition of this $\mathrm{GABA}_{A}$ receptor is of great influence on the effects observed; certain traits of benzodiazepines are mediated by specific subunits (Rudolph et al. 1999). Although pharmacokinetic and metabolic factors as well as differences in activity and size of the animals may have contributed to differential effects of diazepam in the three strains, differences between mouse strains in their sensitivity toward benzodiazepines probably result from differential $\mathrm{GABA}_{A}$ receptor subunit composition and quantity in specific brain regions (i.e. amygdala).

When interpreting pharmacological data, distinct strain differences in sensitivity to diazepam become clear in both BT and HR. Anxiolytic effects of diazepam are associated with activation of the $\mathrm{GABA}_{\mathrm{A}} \alpha_{2}$ subunit (Rudolph et al. 2001; Vicini \& Ortinski 2004), and in the present experiments such effects are reflected in $\Delta \mathrm{BT}$ and $\Delta \mathrm{HR}$ after presentation of the rectal stressor. All three strains show an anxiolytic response to diazepam, the 12956 strain being most sensitive, and in spite of reduced sensitivity in the B6, strain significant reductions in $\Delta \mathrm{BT}$ and $\Delta \mathrm{HR}$ are found at higher doses of diazepam. The strong effect on baseline BT seen only in the 12956 strain indicates a hypothermic effect, with an average decrease of $2{ }^{\circ} \mathrm{C}$ after $8-\mathrm{mg} / \mathrm{kg}$ diazepam injection. In humans, it has been suggested that heat loss is a key pathway of generating sleepiness and sedation and is associated with the GABA $\alpha_{1}$ subunit (Echizenya et al. 2003). This strong intrinsic effect on BT suggests a higher number of $\alpha_{1}$ subunits in this strain in brain areas involved in temperature regulation, and consequently, a more sedative effect of diazepam could be effected. The open field, elevated plus maze and light/dark box are frequently used examples of approach-avoidance paradigms in which anxiety is reflected as natural aversive behavior of rodents to brightly lit, open areas, and anxiolytic drugs have been found effective (Belzung \& Griebel 2001; Finn et al. 2003; Kim et al. 2002; van Gaalen \& Steckler 2000). Our results show that anxiolytic effects of diazepam also can be measured using autonomic parameters and $\mathrm{SIH}$, with the advantage of excluding the effects of strain differences in LA.

Combining results on circadian rhythm, stress response and pharmacological sensitivity, these experiments give increased insight in dynamics of autonomic parameters in mice. Three different mouse strains were included in the experiments, and differences between the strains both in reaction to stress as well as in pharmacological sensitivity were present. It is found that reactions in autonomic parameters are not necessarily being reflected in or caused by increased activity.

This underlines the importance of carefully choosing a strain when performing experiments in anxiety research. With these experiments, we furthermore demonstrate that autonomic parameters prove to be valuable parameters to provide information on mechanisms underlying stress and anxiety disorders.

\section{References}

Bailey, S.J. \& Toth, M. (2004) Variability in the benzodiazepine response of serotonin 5 -HT1A receptor null mice displaying 


\section{Van Bogaert et al.}

anxiety-like phenotype: evidence for genetic modifiers in the 5-HT-mediated regulation of GABA (A) receptors. J Neurosci 28, 6343-6351.

Belzung, C. \& Griebel, G. (2001) Measuring normal and pathological anxiety-like behaviour in mice: a review. Behav Brain Res 1-2, 141-149.

Bouwknecht, J.A., Hijzen, T.H., van der G.J., Maes, R.A. \& Olivier, B. (2000) Stress-induced hyperthermia in mice: effects of flesinoxan on heart rate and body temperature. Eur $J$ Pharmacol 1, 59-66.

Bouwknecht, J.A., van der Gugten, J., Groenink, L., Olivier, B. \& Paylor, R.E. (2004) Effects of repeated testing in two inbred strains on flesinoxan dose-response curves in three mouse models for anxiety. Eur J Pharmacol 1, 35-44.

Carola, V., D'Olimpio, F., Brunamonti, E., Mangia, F. \& Renzi, P. (2002) Evaluation of the elevated plus-maze and open-field tests for the assessment of anxiety-related behaviour in inbred mice. Behav Brain Res 1-2, 49.

Connolly, M.S. \& Lynch, C.B. (1981) Circadian variation of strain differences in body temperature and activity in mice. Physiol Behav 6, 1045-1049.

Contet, C., Rawlins, J.N. \& Deacon, R.M. (2001) A comparison of 129S2/SvHsd and C57BL/6JOlaHsd mice on a test battery assessing sensorimotor, affective and cognitive behaviours: implications for the study of genetically modified mice. Behav Brain Res 1, 33-46.

Crabbe, J.C., Wahlsten, D. \& Dudek, B.C. (1999) Genetics of mouse behavior: interactions with laboratory environment. Science 5420, 1670-1672.

Crawley, J.N., Belknap, J.K., Collins, A., Crabbe, J.C., Frankel, W., Henderson, N., Hitzemann, R.J., Maxson, S.C., Miner, L.L., Silva, A.J., Wehner, J.M., Wynshaw-Boris, A. \& Paylor, R. (1997) Behavioral phenotypes of inbred mouse strains: implications and recommendations for molecular studies. Psychopharmacology (Berl) 2, 107-124.

Echizenya, M., Mishima, K., Satoh, K., Kusanagi, H., Sekine, A., Ohkubo, T., Shimizu, T. \& Hishikawa, Y. (2003) Heat loss, sleepiness, and impaired performance after diazepam administration in humans. Neuropsychopharmacology 6, 1198-1206.

Finn, D.A., Rutledge-Gorman, M.T. \& Crabbe, J.C. (2003) Genetic animal models of anxiety. Neurogenetics 3, 109-135.

Friedman, B.H. \& Thayer, J.F. (1998a) Anxiety and autonomic flexibility: a cardiovascular approach. Biol Psychol 3, 243-263.

Friedman, B.H. \& Thayer, J.F. (1998b) Autonomic balance revisited: panic anxiety and heart rate variability. J Psychosom Res 1, 133-151.

van Gaalen, M.M. \& Steckler, T. (2000) Behavioural analysis of four mouse strains in an anxiety test battery. Behav Brain Res 1, 95-106.

Goodwin, F.K., Wirz-Justice, A. \& Wehr, T.A. (1982) Evidence that the pathophysiology of depression and the mechanism of action of antidepressant drugs both involve alterations in circadian rhythms. Adv Biochem Psychopharmacol 32, 1-11.

Griebel, G., Belzung, C., Perrault, G. \& Sanger, D.J. (2000) Differences in anxiety-related behaviours and in sensitivity to diazepam in inbred and outbred strains of mice. Psychopharmacology (Berl) 2, 164-170.

Homanics, G.E., Quinlan, J.J. \& Firestone, L.L. (1999) Pharmacologic and behavioral responses of inbred C57BL/6J and strain 129/SvJ mouse lines. Pharmacol Biochem Behav 1, 21-26.
Iverson, G.L., Stampfer, H.G. \& Gaetz, M. (2002) Reliability of circadian heart pattern analysis in psychiatry. Psychiatr Q 3, 195-203.

Kelly, M.A., Rubinstein, M., Phillips, T.J., Lessov, C.N., BurkhartKasch, S., Zhang, G., Bunzow, J.R., Fang, Y., Gerhardt, G.A., Grandy, D.K. \& Low, M.J. (1998) Locomotor activity in D2 dopamine receptor-deficient mice is determined by gene dosage, genetic background, and developmental adaptations. J Neurosci 9, 3470-3479.

Kim, S., Lee, S., Ryu, S., Suk, J. \& Park, C. (2002) Comparative analysis of the anxiety-related behaviors in four inbred mice. Behav Processes 2, 181-190.

Lesch, K.P. (1991) 5-HT1A receptor responsivity in anxiety disorders and depression. Prog Neuropsychopharmacol Biol Psychiatry 6, 723-733.

Meerlo, P., De Boer, S.F., Koolhaas, J.M., Daan, S. \& Van den Hoofdakker, R.H. (1996) Changes in daily rhythms of body temperature and activity after a single social defeat in rats. Physiol Behav 4-5, 735-739.

Montkowski, A., Poettig, M., Mederer, A. \& Holsboer, F. (1997) Behavioural performance in three substrains of mouse strain 129. Brain Res 1-2, 12-18.

Mortola, J.P. \& Lanthier, C. (2004) Scaling the amplitudes of the circadian pattern of resting oxygen consumption, body temperature and heart rate in mammals. Comp Biochem Physiol a Mol Integr Physiol 1, 83-95.

Nijsen, M.J., Croiset, G., Diamant, M., Broekhoven, M.H., De Wied, D. \& Wiegant, V.M. (1998) Vagal activation in novelty-induced tachycardia during the light phase in the rat. Physiol Behav 2, 233-239.

Olivier, B., Zethof, T.J., Ronken, E. \& van der Heyden, J.A. (1998) Anxiolytic effects of flesinoxan in the stress-induced hyperthermia paradigm in singly-housed mice are 5-HT1A receptor mediated. Eur J Pharmacol 2-3, 177-182.

Olivier, B., Zethof, T., Pattij, T., van Boogaert, M., van Oorschot, R., Leahy, C., Oosting, R., Bouwknecht, A., Veening, J., van der Gugten, J. \& Groenink, L. (2003) Stress-induced hyperthermia and anxiety: pharmacological validation. Eur J Pharmacol 1-3, 117-132.

Overton, J.M. \& Williams, T.D. (2004) Behavioral and physiologic responses to caloric restriction in mice. Physiol Behav 5, 749-754.

Pattij, T., Groenink, L., Hijzen, T., Oosting, R., van der Maes, R., G.J. \& Olivier, B. (2002) Autonomic changes associated with enhanced anxiety in 5-HT (1A) receptor knockout mice. Neuropsychopharmacology 3, 380.

Paulus, M.P., Dulawa, S.C., Ralph, R.J. \& Mark, A.G. (1999) Behavioral organization is independent of locomotor activity in 129 and C57 mouse strains. Brain Res 1, 27-36.

Ricquier, D. \& Bouillaud, F. (2000) Mitochondrial uncoupling proteins: from mitochondria to the regulation of energy balance. J Physiol 529, 3-10.

Rodgers, R.J., Boullier, E., Chatzimichalaki, P., Cooper, G.D. \& Shorten, A. (2002a) Contrasting phenotypes of C57BL/ $6 J O l a H s d, 129 \mathrm{~S} 2 / \mathrm{SvH}$ sd and 129/SvEv mice in two exploration-based tests of anxiety-related behaviour. Physiol Behav 2-3, 301-310.

Rodgers, R.J., Davies, B. \& Shore, R. (2002b) Absence of anxiolytic response to chlordiazepoxide in two common background strains exposed to the elevated plus-maze: importance and implications of behavioural baseline. Genes Brain Behav 4, 242-251. 
Rudolph, U., Crestani, F., Benke, D., Brunig, I., Benson, J.A., Fritschy, J.M., Martin, J.R., Bluethmann, H. \& Mohler, H. (1999) Benzodiazepine actions mediated by specific gammaaminobutyric acid (A) receptor subtypes. Nature 6755, 796-800.

Rudolph, U., Crestani, F. \& Mohler, H. (2001) GABA (A) receptor subtypes: dissecting their pharmacological functions. Trends Pharmacol Sci 22, 188-194.

Sibille, E., Pavlides, C., Benke, D. \& Toth, M. (2000) Genetic inactivation of the serotonin (1A) receptor in mice results in downregulation of major GABA (A) receptor alpha subunits, reduction of GABA (A) receptor binding, and benzodiazepineresistant anxiety. J Neurosci 20, 2758-2765.

Tang, X., Orchard, S.M. \& Sanford, L.D. (2002) Home cage activity and behavioral performance in inbred and hybrid mice. Behav Brain Res 136, 555-569.

Toth, M. (2003) 5-HT (1A) receptor knockout mouse as a genetic model of anxiety. Eur J Pharmacol 1-3, 177-184.

Tulen, J.H., Bruijn, J.A., de Man, K.J., van der Velden, E., Pepplinkhuizen, L., Man in't. Veld, A.J. (1996) Anxiety and autonomic regulation in major depressive disorder: an exploratory study. J Affect Disord 1-2, 61-71.

Vicini, S. \& Ortinski, P. (2004) Genetic manipulations of GABAA receptor in mice make inhibition exciting. Pharmacol Ther 2, 109-120.
Wahlsten, D., Metten, P., Phillips, T.J., Boehm, S.L., II, Burkhart-Kasch, S., Dorow, J., Doerksen, S., Downing, C., Fogarty, J., Rodd-Henricks, K., Hen, R., McKinnon, C.S., Merrill, C.M., Nolte, C., Schalomon, M., Schlumbohm, J.P., Sibert, J.R., Wenger, C.D., Dudek, B.C. \& Crabbe, J.C. (2003) Different data from different labs: lessons from studies of gene-environment interaction. J Neurobiol 1, 283-311.

Wehr, T.A. \& Wirz-Justice, A. (1982) Circadian rhythm mechanisms in affective illness and in antidepressant drug action. Pharmacopsychiatria 1, 31-39.

Williams, T.D., Chambers, J.B., Henderson, R.P., Rashotte, M.E. \& Overton, J.M. (2002) Cardiovascular responses to caloric restriction and thermoneutrality in C57BL/6J mice. Am J Physiol Regul Integr Comp Physiol 5, R1459-R1467.

\section{Acknowledgment}

The authors thank Meg Breuer, Tommy Pattij, Ruud van Oorschot and Marijke de Graaff for their technical assistance during surgery and experiments. 